\title{
Emerging Insights into the Roles of Membrane Tethers from Analysis of Whole Organisms: The Tip of an Iceberg?
}

\author{
Wei Hong Toh and Paul A. Gleeson * \\ The Department of Biochemistry and Molecular Biology, Bio21 Molecular Science and Biotechnology Institute, The University \\ of Melbourne, Melbourne, VIC, Australia
}

Membrane tethers have been identified throughout different compartments of the endomembrane system. It is now well established that a number of membrane tethers mediate docking of membrane carriers in anterograde and retrograde transport and in regulating the organization of membrane compartments. Much of our information on membrane tethers have been obtained from the analysis of individual membrane tethers in cultured cells. In the future it will be important to better appreciate the network of interactions mediated by tethers and the potential co-ordination of their collective functions in vivo. There are now a number of studies which have analyzed membrane tethers in tissues and organisms which are providing new insights into the role of this class of membrane protein at the physiological level. Here we review recent advances in the understanding of the function of membrane tethers from knock outs (or knock downs) in whole organisms and from mutations in tethers associated with disease.

Keywords: membrane tethers, endomembrane system, whole organisms, knock-outs, membrane trafficking

Reviewed by:
Bettina Winckler,

University of Virginia, USA

Julie G. Donaldson,

National Institutes of Health, USA

*Correspondence:

Paul A. Gleeson

pgleeson@unimelb.edu.au

Specialty section:

This article was submitted to

Membrane Traffic,

a section of the journal

Frontiers in Cell and Developmental

Biology

Received: 29 November 2015 Accepted: 08 February 2016

Published: 29 February 2016

Citation:

Toh WH and Gleeson PA (2016) Emerging Insights into the Roles of Membrane Tethers from Analysis of

Whole Organisms: The Tip of an Iceberg? Front. Cell Dev. Biol. 4:12.

doi: 10.3389/fcell.2016.00012

\section{WHAT ARE MEMBRANE TETHERS?}

Membrane trafficking is a dynamic process which involves the generation of transport vesicles loaded with cargo and their delivery and fusion to their designated compartments. Vesicle docking represents a key step in this process whereby transport vesicles or carriers are delivered with high fidelity to target membranes. Tethering factors play a central role in the docking process as they mediate the bridging of the vesicle and target membranes. Loss of membrane tethers impacts not only on membrane transport but also in many cases on the organization of intracellular compartments suggesting additional roles for tethers in organelle biogenesis.

The majority of membrane tethers are recruited from the cytoplasm by Rab and Arl small G proteins to a defined intracellular location such as the Golgi apparatus or the early endosome. The recruitment of these peripheral membrane proteins provides a dynamic mechanism to establish specialized protein complexes within defined membrane subdomains. Membrane tethers interact with Rabs and SNARES (soluble NSF attachment protein receptors) for co-ordinating docking and fusion. SNARE proteins are crucial for vesicle fusion following the docking event. Membrane docking mediated by tethers provides the first level of specificity as well as promoting the shorter range interaction between SNARE molecules on opposing membranes which then promotes membrane fusion.

Membrane tethers interact not only with Rabs and SNAREs but also with other effectors, such as cytoskeletal components, which suggests membrane tethers have functions in addition 
to the regulation of docking of membrane transport carriers (Chia and Gleeson, 2014). There is considerable ongoing effort to define the set of interactive partners for each membrane tether and for details on these interactions the reader is directed to recent reviews which summarize this topic (Bröcker et al., 2010; Yu and Hughson, 2010; Munro, 2011; Solinger and Spang, 2013; Chia and Gleeson, 2014). Many of the studies exploring the interactive partners and functions of membrane tethers have used cultured cells and yeast. These studies have revealed insights into specific roles of membrane tethers in membrane transport and organelle biogenesis. Also recent studies have begun to explore the roles of membrane tethers in tissues and specialized cells and these investigations have revealed a broader appreciation of their cellular and physiological importance. In many cases the outcome of these in vivo studies would not have been predicted from the knowledge of the function of membrane tethers in cultured cells, illustrating the potential limitations of the use of cell lines. Therefore, we think it timely to highlight the recent in vivo studies exploring the roles of membrane tethers in whole tissues and organisms which is the main focus of this review.

\section{CLASSIFICATION OF TETHERS}

Tethering factors can be widely classified into two major classes-long coiled-coil proteins and multi-subunit tethering complexes (MTCs). Coiled-coil tethers are typically hydrophilic homodimeric proteins containing extensive regions of coiledcoil domains; typically there are discontinuities in the coiledcoil domains which are proposed to provide flexible joints in the molecules to allow the tether to mediate docking of bound transport vesicles onto the target membrane. MTCs are a diverse family of proteins consisting of 3 to 10 subunits with sizes up to $800 \mathrm{kDa}$ (Bröcker et al., 2010). The MTC are predicted to interact with vesicles within a shorter distance from the membrane than the more extended coiled-coil tethers. Both classes of tethering factors can be found throughout the secretory and endocytic pathways (Yu and Hughson, 2010; Chia and Gleeson, 2014). Coiled-coil tethers include golgins, found extensively distributed throughout the Golgi apparatus and the early endosome tether, EEA1, while MTCs include COG (conserved oligomeric Golgi complex), GARP (Golgi-associated retrograde protein complex), Vps (class C vacuolar protein-sorting) complexes, exocyst, HOPS (homotypic fusion and vacuole protein sorting), and CORVET (class $\mathrm{C}$ core vacuole/endosome tethering) (reviewed in $\mathrm{Yu}$ and Hughson, 2010; Chia and Gleeson, 2014).

\section{Golgins}

Golgins are a family of Golgi associated coiled-coil proteins that are required for vesicle docking as well as Golgi integrity (Barr and Short, 2003; Short et al., 2005; Ramirez and Lowe, 2009). Golgins are localized predominantly to the cis and the trans face of the Golgi. The differential localization of different golgins reflects distinct roles for each protein. As golgins have extensive coiled-coil regions, they have the ability to project into the cytosol as long extensions of up to $\sim 200 \mathrm{~nm}$ (Orci et al., 1998). It is proposed that these long coiled-coil regions can facilitate specificity of vesicle traffic to the Golgi (Wong and
Munro, 2014). Rab1 golgin effectors, GM130, p115, and giantin have been shown to form a complex to tether anterograde COPII vesicles as well as retrograde COPI transport vesicles (Ramirez and Lowe, 2009). Different sets of tethering complexes have been reported to recruit different subpopulations of vesicles conferring a level of vesicle tethering specificity (Malsam et al., 2005). For example, other golgins like CASP (CCAAT-Displacement Protein Transcription Factor) can interact with golgin84 to mediate retrograde trafficking of vesicles containing Golgi enzymes (Diao et al., 2003; Malsam et al., 2005). Another golgin present in the Golgi-matrix is GMAP210 (Rios et al., 1994; Infante et al., 1999) which is recruited to the Golgi by the small G protein, Arf1 (Gillingham et al., 2004). The N-terminal sequence of GMAP210 consists of an amphipathic ALPS (ArfGAP1 Lipid Packing Sensor) motif which has a preference to bind to highly curved membranes whereas the C-terminal preferentially bind to flat membranes leading to the model that GMAP210 is able to tether flat membrane of the cisternae to the curved membranes of tubules or vesicles (Drin et al., 2007, 2008).

Tethering factors located on the trans-face of the Golgi play a role in early endosome to TGN transport. Coiled-coil tethering factors located on the TGN include the GRIP-domain golgins (golgin97, p230, GCC185, and GCC88) (Gleeson et al., 2004). These factors play an important role in retrograde transport of various cargo from the early, recycling and late endosomes to the TGN.

There is also increasing evidence that golgins have a role in the maintenance of the Golgi stack and ribbon by their interactions with the cytoskeleton. GRASP65 and GM130 has been reported to facilitate Golgi ribbon formation (Sonnichsen et al., 1998; Grabski et al., 2012). GM130 targets GRASP65 to the periphery of the cis-cisternae allowing GRASP65 to promote linking of the cisternae (Puthenveedu et al., 2006). In addition, GM130 is able to recruit $\gamma$-tubulin to the cis-Golgi via AKAP450 (A-kinase anchoring protein 450) thus allowing microtubule nucleation which facilitate Golgi ribbon formation (Rivero et al., 2009). GMAP210 has also been shown to recruit $\gamma$-tubulin to the cisGolgi to facilitate Golgi ribbon formation (Linstedt, 2004).

\section{MTCs}

MTCs such as COG, Dsl1p, and GARP are found to localize to the Golgi where they have been shown to mediate anterograde or retrograde transport of cargoes. Exocyst, HOPs and CORVET are localized to the endo-lysosomal system where they mediate tethering and fusion of transport carriers between the endosomes or from the endosome to the plasma membrane. MTCs can consist of 3 to 10 subunits that differ in size from 50 to $140 \mathrm{kDa}$ per subunit. This indicates that a combination of different functions within one protein complex. As MTCs do not contain coiled-coil regions, their tethering range is reduced to $\sim 30 \mathrm{~nm}$ rather than $>200 \mathrm{~nm}$ like the golgins. However, this range is still sufficient for the capturing of vesicles. MTCs, like the golgins, interact with Rab-GTPases and SNAREs. Binding of the MTCs to different interacting partners confers specificity to the pathways that they regulate. For example, the GARP complex has been shown to tether vesicles positive for M6PR to the TGN membranes (Perez-Victoria et al., 2008). Recruitment 
of the GARP complex to the TGN is regulated by Rab6 and is thought to promote SNARE interactions (Liewen et al., 2005). Two SNARE complexes together with the GARP tether have been implicated in the transport from the endosomes to the TGN; the syntaxin16/syntaxin6/Vtila/Vamp3 or Vamp4 complex (Mallard et al., 2002; Amessou et al., 2007) and the syntaxin5/GS15/GS28/Ykt6 SNARE complex (Tai et al., 2004), and these SNARE complexes probably regulate different retrograde transport pathways.

\section{ELUCIDATING THE FUNCTIONS OF TETHERS IN WHOLE ORGANISMS}

There has been considerable advance over the past 10 years in defining the biochemistry of membrane tethers and their intracellular location and functional roles in cultured cells (Bröcker et al., 2010; Yu and Hughson, 2010; Munro, 2011; Solinger and Spang, 2013; Chia and Gleeson, 2014). The stage is now set to better appreciate the functions of tethers within specialized cell types and tissues. Given the diverse set of effectors which interact with tethers, genetic approaches provide a powerful strategy for defining the function of membrane tethers in a physiological setting.

A number of genetic approaches have been used to genetically alter membrane tether genes and these experiments have resulted in a variety of developmental and physiological phenotypes in a range of organisms which have been studied. As membrane tethers have a suite of binding partners, any phenotype observed in whole organisms needs to be interpreted within the context of the consequence of the genetic alteration on the biochemistry of the membrane tether and its interactions with binding partners. Figure 1 summaries some of the theoretical possibilities arising from different approaches where the class of coiled-coil membrane tethers are genetically altered. Knock-down by RNAi will result in a reduction in the level of the tether, however, depending on the efficiency of the RNAi, low to modest levels of the tether are likely to remain. On the other hand, gene knock outs by targeted mutagenesis could result in a variety of outcomes depending on the site of targeting; this includes a null allele where the membrane tether is completely absent to the expression of a truncated protein. Truncated versions of tethers which lack their intracellular targeting domain will not be recruited to the membrane and would result in loss of function of the tether. However, and in contrast to a null allele, truncated cytoplasmic versions may interact with effectors and such interactions may have indirect effects in the cell. Likewise, $N$-ethyl- $N$-nitrosourea (ENU) mutagenesis can result in a loss of function of a gene by the insertion of a nonsense mutation and the production of a truncated protein. Disease causing mutations may be missense or nonsense mutations, resulting in a truncated protein or mutations in the coding region which perturb the binding to one (or more) binding partners. If the tethers are involved in a range of biological functions then the resulting phenotypes of different genetic alterations will likely reflect the consequence of the interactions of the tether, not only with the membrane compartment where the tether is normally localized, but also with specific binding partners. Indeed, the use of different genetic approaches for a given tether is likely to provide complimentary information in unraveling the functions of these molecules.

The following describes the findings for genetic manipulation of individual membrane tethers of both the secretory pathway and endocytic pathways in mice, Caenorhabditis elegans and Drosophila melanogaster and zebrafish as well as disease causing mutations in humans. Figure 2 and Table 1 summarize the identity and localization of the tethers that have been mutated in animal models and those that have been identified to be mutated in disease.

\section{cis-Golgi Network USO1/p115}

The golgin Usolp/p115 is a coiled-coil tether localized to the cis-Golgi and knockdown in cultured cells has been shown to result in disruption of the normal Golgi structure (Alvarez et al., 2001; Sohda et al., 2005; Radulescu et al., 2011). In cultured cells, p115 has been shown to interact with other Golgi proteins such as GM130 (Nakamura et al., 1997), giantin (Sonnichsen et al., 1998) to form a triad of tethers that is integral to maintaining Golgi architecture as well as tethering of COPI vesicles (Sonnichsen et al., 1998). Knockouts in mouse (mixed 129 and C57BL/6 backgrounds), involving a functionally null allele, caused Golgi disruption and early embryonic lethality where death occurred between embryonic day 3 and 8.5 (Kim et al., 2012). Embryonic lethality suggests that USO1/p115 is critical for early development rather than cell survival per se. Interestingly, the loss of USO1 appeared to result in perturbation of the Golgi structure in only certain cell types suggesting that some cell types may be more susceptible to the absence of the USO1 golgin (Kim et al., 2012).

\section{Giantin}

Giantin is a type II membrane protein tether which have been identified in cultured cells and C. elegans to interact with other golgins, namely p115 and GM130, an interaction considered to be important in mediating docking of COPI vesicles (Grabski et al., 2012; Sonnichsen et al., 1998). A linkage analysis to map the candidate gene responsible for the spontaneously arising mutation osteochondrodysplasmia (OCD) in a rat colony led to the identification of a 10-bp insertion in the gene that encodes rat giantin (Golgh1) (Katayama et al., 2011). Mutant inbred rats that are homozygous for the $O C D$ (Osteochondrodysplasia) gene develop osteochondrodysplasia, cleft palate, and system edema. These rats are born with an abnormal skeletal system (Suzuki et al., 1987) and suffer from early post-natal lethality due to respiratory inadequacy (Kikukawa et al., 1989). The identified 10-bp insertion is in exon 13 of the Golgh1 gene resulting in a truncation of the giantin protein which lacks the $\mathrm{C}$-terminal two-thirds of the protein. The $\mathrm{C}$-terminus of giantin is required for localization to the Golgi and the OCD mutation is predicted to result in a loss of function of giantin (Katayama et al., 2011). However, it remains a possibility that the truncated giantin protein may also display activities which contribute to the phenotype in these mice (Katayama et al., 2011). The striking phenotype associated with mutant giantin suggests that golgins are critical for the normal development of the muscular-skeletal 


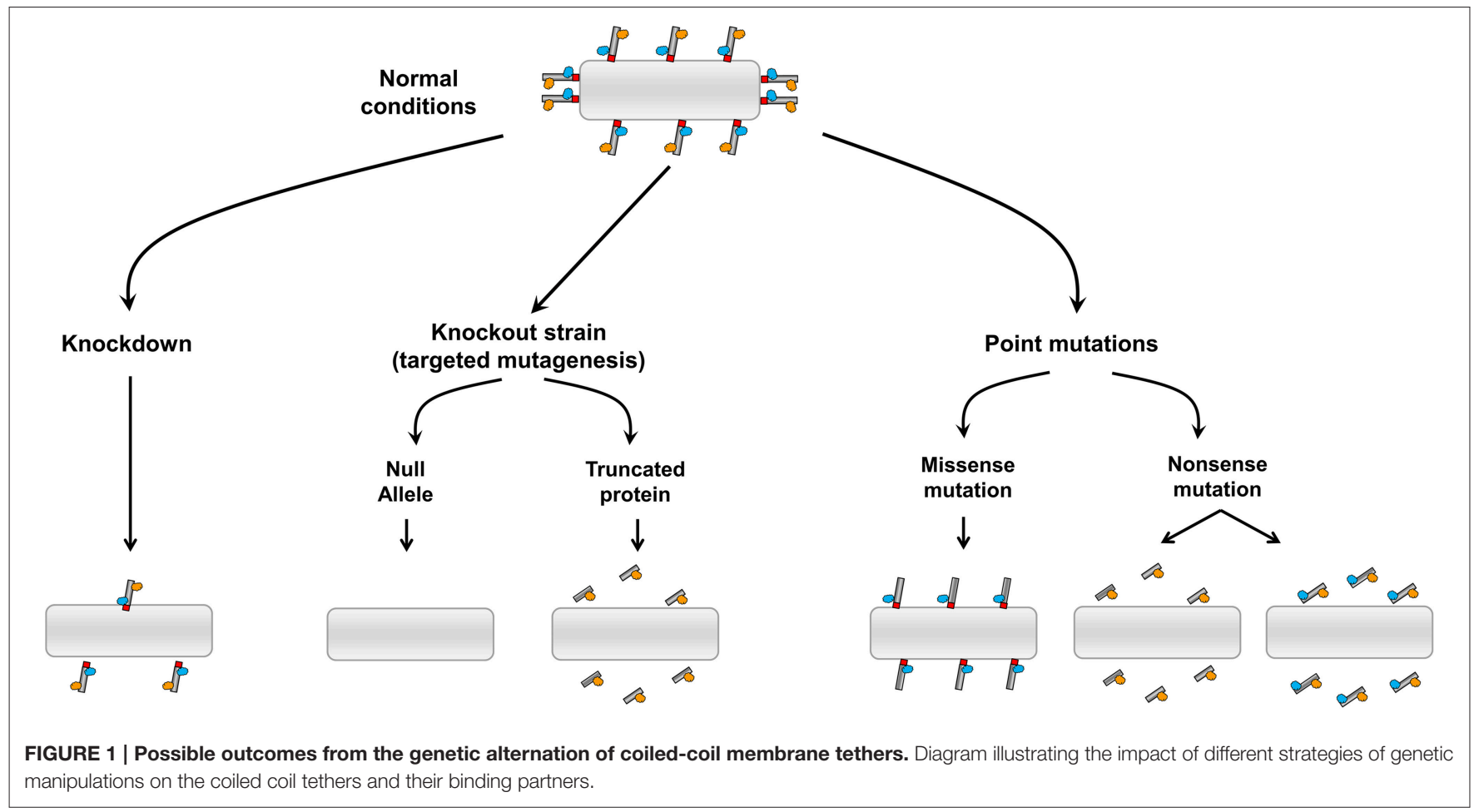

system. However, further study is required to understand why the mutations in the giantin gene result in these phenotypes.

\section{GMAP210}

GMAP210 is a coiled-coil golgin localized to the cis-Golgi. It is recruited to the Golgi by the interaction of its C-terminal domain with the small $G$ protein Arf1 while the N-terminal domain interacts with curved regions of membranes (Mesmin et al., 2007; Drin et al., 2008). Depletion of GMAP210 in cultured cells has been shown to result in Golgi fragmentation of the ribbon structure, but not disruption to the organization of the Golgi stack nor an effect on the rate of secretory traffic (Rios et al., 2004; Yadav et al., 2009). A possible role for GMAP210 in cilium formation is suggested by the finding that GMAP210 is required for the Golgi localization of intraflagellar transport protein 20 (IFT20), a protein involved in cilia formation (Follit et al., 2008). Moreover, mutations that knockout GMAP210 in mice (Follit et al., 2008) and C. elegans (Broekhuis et al., 2013) results in defective ciliogenesis. Analysis of mouse and C. elegans deletion mutations suggest these are null alleles (Follit et al., 2008; Broekhuis et al., 2013). Cells derived from the GMAP210-knockout mice reported by Follit et al. (2008) do not show structural defects of the Golgi, raising the possibility that GMAP210 may not be required for Golgi organization in many cells in vivo. More recently, other studies have reported that a lack of GMAP210 in mice and humans results in neonatal lethal skeletal dysplasia achondrogenesis type 1A (Smits et al., 2010). GMAP-210 mutant mice were derived from an ENU mutagen screen and a nonsense mutation in the coding region of GMAP210 identified at position L1668. No protein was detected in cell extracts by immunoblotting, using an antibody that recognizes an epitope $\mathrm{N}$-terminal of the nonsense mutation, suggesting that the GMAP-210 protein was absent. Mice with this GMAP210 mutation die shortly after birth and have multiple phenotypes such as skeletal, heart and lung deformities (Smits et al., 2010). In contrast to the earlier study by Follit et al. (2008), cells derived from GMAP210 mutant mice showed disruption in Golgi organization and defects in secretion of extracellular matrix components (Smits et al., 2010). The defects in secretion are likely to arise from the lack of Golgimediated glycosylation, indicating that GMAP210 is involved in glycosylation and intracellular transport. Strikingly 10 patients with a related disease to the phenotype of the GMAP210 mutant mice, achondrogenesis $1 \mathrm{~A}$, were shown to have loss-of-function mutations in the gene encoding GMAP210 (Smits et al., 2010). Further studies are required to reconcile the phenotypes of the two lines of GMAP210-deficient mice which show defects in either ciliogenesis or skeletogenesis.

\section{Golgi Stack}

\section{Conserved Oligomeric Golgi (COG) Complex}

The COG complex is a multisubunit tethering complex (MTC) localized to the Golgi apparatus that is involved in mediating retrograde Golgi transport (Lees et al., 2010). Loss of COG complexes in cells results in expansion of Golgi cisternae and mislocalization and rapid turnover of a number of Golgi glycosyltransferases, leading to the conclusion that COG complexes may be responsible for the proper trafficking and function of glycosyltransferases in the cell (Kingsley et al., 1986). The heteromeric COG complex consists of 8 subunits (COG18) arranged in two lobes. Yeast that lack COG1 show severe growth defects (Whyte and Munro, 2001; Deutschbauer et al., 


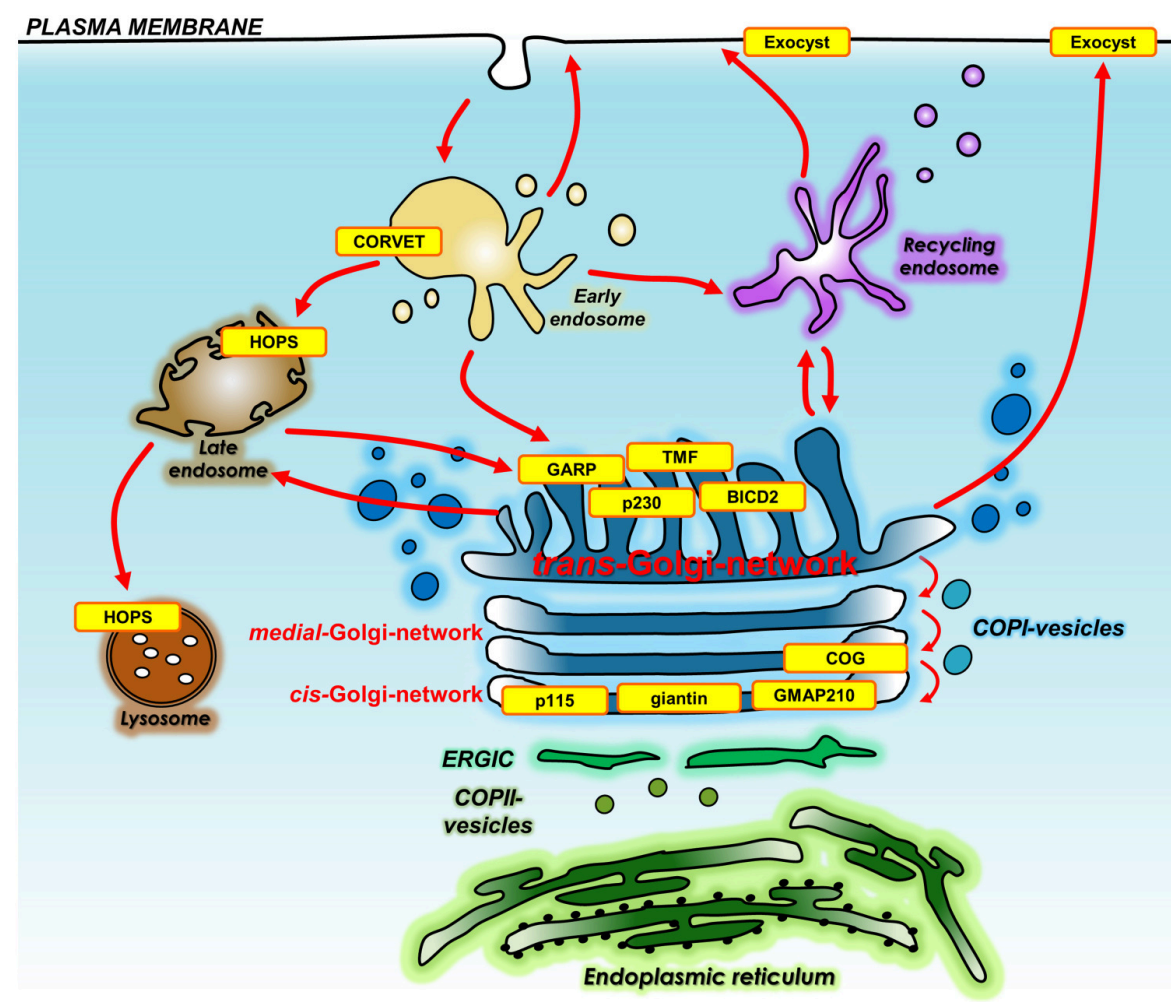

FIGURE 2 | Location of membrane tethers either knocked out in whole organisms or mutated in human diseases. Shown is the location and identity of the membrane tethers (yellow) that have been knocked out in whole organisms or have been found mutated in human diseases. Also shown are the transport pathways that are regulated by membrane tethers. Membrane tethers include those localized to the Golgi, endo-lysosomal system, and plasma membrane. BICD2, Bicaudal D-2; COG, conserved oligomeric Golgi complex; CORVET, class C core vacuole/endosome tethering; GARP, Golgi associated retrograde protein; GMAP210, Golgi microtubule-associated protein of $210 \mathrm{kDa}$; HOPS, homotypic fusion and vacuole protein sorting; TMF, TATA element modulatory factor/androgen receptor-coactivator of $160 \mathrm{kDa}$; p230, golgin245.

2005) while deficiencies in COG5, 6, 7, and 8 in yeast lead to milder defects (Whyte and Munro, 2001). To date, eight patients from five different families have been identified with COG7 deficiencies and these patients show congenital hypotonia, perinatal asphyxia, progressive microcephaly, feeding difficulties and cardiac abnormalities (Wu et al., 2004; Morava et al., 2007; $\mathrm{Ng}$ et al., 2007). Deficiency in COG1 has been described in one patient who displayed a similar phenotype as the patients with a COG7 deficiency which included generalized hypotonia, feeding problems at birth, and growth retardation. Two patients have been described with a COG8 deficiency (Foulquier et al., 2007; Kranz et al., 2007). These COG8-deficient patients also showed hypotonia, acute encephalopathy, loss of psychomotor abilities and mental retardation. A range of mutations in the COG subunits have been identified in patients including splice mutations, nonsense mutations, and deletions. It is likely that the phenotypes described above have arisen from dysfunctional glycosylation in the cell, due to a block in intra-Golgi retrograde trafficking due to a deficiency in the COG membrane tether.

\section{trans-Golgi Network Bicaudal-D2 (BICD2)}

BICD2 is a golgin localized to the TGN which binds to the dynamitin subunit of dynactin (Matanis et al., 2002).
Dynactin acts as an adaptor between motor proteins and cargo to facilitiate the transport of membrane vesicles. Missense mutations in BICD2 have been identified in patients with congenital autosomal-dominant spinal muscular atrophy (SMA) within Dutch and Bulgarian families (Neveling et al., 2013; Oates et al., 2013; Peeters et al., 2013). Mutations in the SMN (spinal motor-neuron) gene are known to also cause SMA and it has recently been shown that the function of the SMN protein is linked to the Golgi network (Ting et al., 2012). Therefore, it is possible that BICD2 may be involved in mediating the transport of the SMN protein.

\section{p230/Golgin 245}

Golgin-245/p230 is a coiled-coil member of the GRIP domain family of TGN golgins. p230 is associated with transport carriers emerging from the TGN (Lock et al., 2005; Lieu et al., 2008) and shown to regulate the transport of specific cargo from the TGN to the cell surface (Kakinuma et al., 2004; Lock et al., 2005; Lieu et al., 2008; Brémond et al., 2009). p230 was identified as an essential regulator of the trafficking of TNF $\alpha$ from the TGN to the cell surface in cultured cells. The function of p230 in the secretion of TNF $\alpha$ in primary macrophages has been examined by silencing p230 in bone marrow stem cells and using these engineered stem cell used to re-constitute irradiated mice (Lieu 
TABLE 1 | Membrane tethers that has been knocked out in whole organisms or has been found mutated in human diseases.

\begin{tabular}{|c|c|c|c|}
\hline Tethers & Structure/Composition & Proposed function & $\begin{array}{l}\text { Phenotype after knockout or mutations } \\
\text { identified in human diseases }\end{array}$ \\
\hline p115/USO1 & $115 \mathrm{kDa}$; homodimer & $\begin{array}{l}\text { Maintenance of Golgi structure; tethering of } \\
\text { COP1 vesicles to Golgi }\end{array}$ & Early embryonic lethality, Golgi disruption in mice \\
\hline Giantin & $400 \mathrm{kDa}$; homodimer & Interacts with $\mathrm{p} 115$ and $\mathrm{GM} 130$ & $\begin{array}{l}\text { Osteochondrodysplasia, cleft palate and system } \\
\text { edema, early post-natal lethaility in mice }\end{array}$ \\
\hline GMAP210 & 210 kDa; homodiner & $\begin{array}{l}\text { Intra-Golgi trafficking and Maintenance of Golgi } \\
\text { structure }\end{array}$ & $\begin{array}{l}\text { Defective ciliogenesis, neonatal lethal skeletal } \\
\text { dysplasia achondrogenesis type } 1 \mathrm{~A} \text {, early post-natal } \\
\text { lethality in mice }\end{array}$ \\
\hline COG & 8 subunits: COG1-8 & Intra-Golgi trafficking & $\begin{array}{l}\text { Mutations identified in human patients associated } \\
\text { with congenital disorders of glycosylation: } \\
\text { congenital hypotonia, perinatal asphyxia, } \\
\text { progressive microcephaly, feeding difficulties and } \\
\text { cardiac abnormalities }\end{array}$ \\
\hline $\mathrm{BICD} 2$ & 98 kDa; homodimer & Binds to dynactin & $\begin{array}{l}\text { Mutations identified in human patients: congenital } \\
\text { autosomal-dominant spinal muscular atrophy (SMA) }\end{array}$ \\
\hline GARP & 4 subunits: Vps51-54 & $\begin{array}{l}\text { Endosome to TGN trafficking; anterograde } \\
\text { transport }\end{array}$ & $\begin{array}{l}\text { Defective spermiogenesis and motor neuron } \\
\text { disease in mice }\end{array}$ \\
\hline HOPS & $\begin{array}{l}6 \text { subunits: Vps } 11 \text {, Vps } 16, V p s 18 \\
\text { Vps33, Vps41, and Vps39 }\end{array}$ & Endosome fusion & $\begin{array}{l}\text { Embryonic lethality in mice, zebrafish and } D \text {. } \\
\text { melanogaster; mutations in human patients linked } \\
\text { to cancer }\end{array}$ \\
\hline CORVET & $\begin{array}{l}6 \text { subunits: Vps11, Vps16, Vps18, } \\
\text { Vps33, Vps8, and Vps3 }\end{array}$ & $\begin{array}{l}\text { Functions upstream of HOPS; endosome } \\
\text { fusion }\end{array}$ & $\begin{array}{l}\text { Growth defects in yeast; embryonic lethality in mice, } \\
\text { zebrafish and } D \text {. melanogaster; mutations in human } \\
\text { patients linked to cancer }\end{array}$ \\
\hline Exocyst & 8 subunits: & $\begin{array}{l}\text { Tethering of transport carriers from recycling } \\
\text { endosome and Golgi }\end{array}$ & $\begin{array}{l}\text { Defective synaptic vesicle fusion, early embryonic } \\
\text { lethality; defective brancing morphogenesis of } \\
\text { tracheal system in } D \text {. melanogaster; }\end{array}$ \\
\hline
\end{tabular}

BICD2, Bicaudal D-2; COG, conserved oligomeric Golgi complex; CORVET, class C core vacuole/endosome tethering; GARP, Golgi associated retrograde protein; GMAP210, Golgi microtubule-associated protein of $210 \mathrm{kDa}$; HOPS, homotypic fusion and vacuole protein sorting; TMF, TATA element modulatory factor/androgen receptor-coactivator of $160 \mathrm{kDa}$.

et al., 2008). Macrophages depleted of p230 were shown to be blocked in the post-Golgi transport of $\mathrm{TNF} \alpha$, demonstrating that membrane tethers of the TGN can regulate post-Golgi trafficking of endogenous cargo in vivo (Lieu et al., 2008).

\section{TMF/ARA160}

TMF/ARA160 (TATA element modulatory factor/androgen receptor-coactivator of $160 \mathrm{kDa}$ ) is a coiled-coil TGN-golgin (Mori and Kato, 2002) which is highly expressed in the testes. TMF has been shown to bind to Rab6 (Fridmann-Sirkis et al., 2004) and is associated with FerT, a testis-specific, Golgi and acrosome-associated tyrosine kinase (Schwartz et al., 1998; Kierszenbaum et al., 2008). Female TMF null mice developed normally and remain fertile. However, male TMF null mice are sterile and their sperm have multiple abnormalities, such as the presence of a round head instead of a normal elongated head, a lack of acrosome and immotile tail (Lerer-Goldshtein et al., 2010). These findings shows that TMF plays a vital role in the differentiation of sperm.

\section{GARP}

GARP is a heterotetrameric complex comprised of 4 subunitsVps51, Vps52, Vps53, and Vps54 (Conibear and Stevens, 2000) and has been shown to be recruited by Rab6 GTPase to the
TGN (Liewen et al., 2005). In cultured cells, GARP has been shown to mediate endosome-to-Golgi retrograde transport of the mannose-6-phosphate receptor and Cholera-toxin B subunit as well as a number of other cargoes (Perez-Victoria et al., 2008). Recently, GARP-mediated retrograde transport has also been shown to be required for post-Golgi trafficking of membrane cargo to the cell surface (Hirata et al., 2015). There is evidence that GARP can bind specific SNAREs to promote SNARE complex assembly at the Golgi and also to tether retrograde transport carriers to the acceptor membrane (Pérez-Victoria and Bonifacino, 2009). Deletion mutants of each GARP subunit were shown to be viable in $C$. elegans. However, knockout of Vps51 in C. elegans showed lysosomal defects (Luo et al., 2011). On the other hand mutations of GARP in the mouse results in a severe phenotype. A mutation in Vps54 in mice ("Wobbler" mouse) which causes a destabilization of the GARP complex has been reported to cause defective spermiogenesis and motor neuron disease (Schmitt-John et al., 2005), while a Vps54 null mutation leads to embryonic lethality (Schmitt-John et al., 2005). The Vps54 knockout embryos showed abnormalities in heart development, absence of dorsal root ganglia and increased apoptosis. Loss of Vps52 in mice led to an earlier embryonic lethality compared with Vps54 null mice where embryos showed 
gastrulation defects (Sugimoto et al., 2012). Collectively, these studies in mutant mice show that the GARP complex is involved in multiple cellular and developmental processes and that different cell types may vary in their requirement for GARP. Clearly, further studies are required to elucidate the binding partners and the pathways regulated by the GARP complex.

\section{Endosomal System HOPs/ CORVET}

HOPs and CORVET are MTCs localized to the endo-lysosomal system in cells where they act sequentially and coordinate tethering and fusion events at the early/late endosomes and the lysosome (Solinger and Spang, 2013; Chia and Gleeson, 2014). HOPS and CORVET share similar core subunit componentsVps11, Vps16, Vps18, and Vps33 (Seals et al., 2000; Peplowska et al., 2007) where both can interact with Rab GTPases and SNAREs. In addition to the core, both complexes contain 2 additional subunits (Vps8 and Vps3 for CORVET and Vps41 and Vps39 for HOPS) which are specific for each complex and show specific Rab binding properties (Price et al., 2000; Wurmser et al., 2000; Peplowska et al., 2007). Interestingly, mutations to any of the core subunits showed severe defects to endosomal biogenesis and vacuolar morphology in yeast (Raymond et al., 1992). Knockouts of HOPS-specific subunits Vps39 and Vps41 in yeast resulted in poor vacuolar fusion (Solinger and Spang, 2013). Knockout of the CORVET specific subunits did not yield significant changes in vacuolar fusion probably because CORVET acts upstream of HOPs. In mouse, zebrafish and Drosophila, knockout of HOPS or CORVET subunits leads to either embryonic lethality (Messler et al., 2011) or severe developmental defects (Sevrioukov et al., 1999; Suzuki et al., 2003; Lo et al., 2005; Schonthaler et al., 2008; Aoyama et al., 2012; Kawamura et al., 2012; Peng et al., 2012). For example, mouse VAM2 is the homolog of yeast Vps41 and conditional knockout of mVAM2 resulted in day 9 embryonic lethality (Aoyama et al., 2012). mVAM2 deficient-cells showed abnormalities in the structure of the late endosomes. Intriguingly, the normal regulation of signaling mediated by the bone morphogenetic protein (BMP) receptor was unable to be terminated in the late endocytic pathway of mVAM2-deficient cells, whereas other signaling pathways such as EGF and TGF- $\beta$ were unaffected (Aoyama et al., 2012). It is noteworthy that BMP signaling is particularly dynamic early in embryonic life. The finding that mutations in HOPS resulted in perturbation in the silencing of activated receptors following endocytosis provides an explanation for the developmental defects in embryogenesis and highlights the importance of studying the function of tethers in whole organisms. Paradoxically, mutations in Vps33 and Vps16 have also been identified in patients with cancer (Gissen et al., 2004; Roy et al., 2011).

\section{Exocyst}

Exocyst is an octameric complex consisting of Sec3, Sec5, Sec6, Sec8, Sec10, Sec15, Exo70, and Exo84 which has been proposed to mediate tethering of transport carriers derived from the recycling endosomes and the Golgi for fusion with the plasma membrane
(Grote et al., 2000; Yeaman et al., 2001; Prigent et al., 2003; Oztan et al., 2007). Binding partners have been identified for the individual exocyst subunits (Heider and Munson, 2012) that include molecules on transport vesicles and on the cell surface. Mutations of exocyst subunits or knock downs in mice, plants and Drosophila are associated with growth and developmental defects. An early study from a gene trap screen in mouse embryonic stem cells identified Sec8 as required for mesoderm induction in embryos (Friedrich et al., 1997). Silencing of the Sec10 in Drosophila resulted in early postembryonic lethality and defined a role for the exocyst in endocrine secretion (Andrews et al., 2002). Knockouts of Sec5 in Drosophila lead to early embryonic lethality and showed normal protein trafficking along the axons but reduced protein cargo delivery into the plasma membrane (Murthy et al., 2003). More recently, the exocyst has been reported in Drosophila to be required for branching morphogenesis of the tracheal system (Jones et al., 2014). Exocyst-deficient cells have branches which are truncated and have an accumulation of vesicles in the cytoplasm, presumably due to a block in fusion with the plasma membrane. The exocyst has also been shown to be involved in ciliogenesis (Das and Guo, 2011; Polgar et al., 2015) and required for epithelial barrier integrity based on use of MDCK cells (Das and Guo, 2011; Polgar et al., 2015). Moreover, a recent study of a conditional knock-out mouse for Sec10 in ureteric bud-derived cells showed that the exocyst was required for ureter development (Fogelgren et al., 2015). Collectively, in vivo studies have demonstrated that the exocyst MTC is required for a range of functions associated with different tissues and organs.

\section{CONCLUSION}

Genetic studies of membrane tethers in mice, C. elegans and Drosophila and the identification of mutations in membrane tethers associated with disease in patients, have revealed a wide range of biological functions for membrane tethers in both the secretory and endocytic transport pathways. Defects in embryogenesis, tissue development, neural networks, and a range of tissue-specific disorders have been identified, particularly muscular-skeletal disease/dysfunctions. These findings demonstrate that the individual tethers are nonredundant factors essential for fundamental cell processes. Given the range of phenotypes associated with these genetic studies, and the differences in susceptibility of different cell types to knocking out or silencing individual tethers, it is likely that many membrane tethers have functions that extend beyond acting as a docking factor for vesicle fusion. Given their multiple binding partners, tethers are likely to co-ordinate a network of interactions which could regulate the establishment of membrane subdomains and the integrity of organelles.

Many mutations of tethering genes are embryonic lethal in mouse and Drosophila. More sophisticated approaches of conditional and inducible knockout systems would be particularly useful to explore the functions of tethers in individual tissues and organs in the adult, as illustrated by the recent studies of the exocyst in ureter function in the mouse (Fogelgren et al., 2015). 
The molecular basis for many of the phenotypes described in this review are not clear and need to be further explored. The binding partners of membrane tethers have mostly been identified in cell lines which has provided an initial framework for defining their function; however, understanding the molecular basis of the cell and tissue-specific phenotypes of membrane tethers in vivo now requires exploration of their binding partners in specific cell types. There may be binding partners of membrane tethers which are cell type specific and which are important for cell type specific functions. The application of a molecular systems biology approach to compare specialized cells from mutant and wild-type organisms should provide a deeper molecular understanding of the precise roles of membrane tethers in vivo. In particular, with the increasing awareness of the cross-talk that exists between different molecular pathways in the cell, it will be of interest to understand how the network

\section{REFERENCES}

Alvarez, C., Garcia-Mata, R., Hauri, H. P., and Sztul, E. (2001). The p115interactive proteins GM130 and giantin participate in endoplasmic reticulumGolgi traffic. J. Biol. Chem. 276, 2693-2700. doi: 10.1074/jbc.M007957200

Amessou, M., Fradagrada, A., Falguières, T., Lord, J. M., Smith, D. C., Roberts, L. M., et al. (2007). Syntaxin 16 and syntaxin 5 are required for efficient retrograde transport of several exogenous and endogenous cargo proteins. J. Cell Sci. 120, 1457-1468. doi: 10.1242/jcs.03436

Andrews, H. K., Zhang, Y. Q., Trotta, N., and Broadie, K. (2002). Drosophila sec10 is required for hormone secretion but not general exocytosis or neurotransmission. Traffic 3, 906-921. doi: 10.1034/j.1600-0854.2002.31206.x

Aoyama, M., Sun-Wada, G. H., Yamamoto, A., Yamamoto, M., Hamada, H., and Wada, Y. (2012). Spatial restriction of bone morphogenetic protein signaling in mouse gastrula through the mVam2-dependent endocytic pathway. Dev. Cell 22, 1163-1175. doi: 10.1016/j.devcel.2012.05.009

Barr, F. A., and Short, B. (2003). Golgins in the structure and dynamics of the Golgi apparatus. Curr. Opin. Cell Biol. 15, 405-413. doi: 10.1016/S09550674(03)00054-1

Brémond, A., Meynet, O., Mahiddine, K., Coito, S., Tichet, M., Scotlandi, K., et al. (2009). Regulation of HLA class I surface expression requires CD99 and p230/golgin-245 interaction. Blood 113, 347-357. doi: 10.1182/blood-2008-02137745

Bröcker, C., Engelbrecht-Vandre, S., and Ungermann, C. (2010). Multisubunit tethering complexes and their role in membrane fusion. Curr. Biol. 20, R943R952. doi: 10.1016/j.cub.2010.09.015

Broekhuis, J. R., Rademakers, S., Burghoorn, J., and Jansen, G. (2013). SQL-1, homologue of the Golgi protein GMAP210, modulates intraflagellar transport in C. elegans. J. Cell Sci. 126, 1785-1795. doi: 10.1242/jcs.116640

Chia, P. Z., and Gleeson, P. A. (2014). Membrane tethering. F1000Prime Rep. 6:74. doi: $10.12703 /$ P6-74

Conibear, E., and Stevens, T. H. (2000). Vps52p, Vps53p, and Vps54p form a novel multisubunit complex required for protein sorting at the yeast late Golgi. Mol. Biol. Cell 11, 305-323. doi: 10.1091/mbc.11.1.305

Das, A., and Guo, W. (2011). Rabs and the exocyst in ciliogenesis, tubulogenesis and beyond. Trends Cell Biol. 21, 383-386. doi: 10.1016/j.tcb.2011.03.006

Deutschbauer, A. M., Jaramillo, D. F., Proctor, M., Kumm, J., Hillenmeyer, M. E., Davis, R. W., et al. (2005). Mechanisms of haploinsufficiency revealed by genome-wide profiling in yeast. Genetics 169, 1915-1925. doi: 10.1534/genetics.104.036871

Diao, A., Rahman, D., Pappin, D. J., Lucocq, J., and Lowe, M. (2003). The coiledcoil membrane protein golgin-84 is a novel rab effector required for Golgi ribbon formation. J. Cell Biol. 160, 201-212. doi: 10.1083/jcb.200207045

Drin, G., Casella, J. F., Gautier, R., Boehmer, T., Schwartz, T. U., and Antonny, B. (2007). A general amphipathic alpha-helical motif for sensing membrane curvature. Nat. Struct. Mol. Biol. 14, 138-146. doi: 10.1038/nsmb1194 of interactions mediated by tethers co-ordinate membrane trafficking and membrane flux in different specialized cell types. It is likely that this information will reveal fundamental insights into the relationship between membrane cell biology and physiological function.

\section{AUTHOR CONTRIBUTIONS}

WHT and PG contributed to the writing of the review and the design of the figures.

\section{ACKNOWLEDGMENTS}

This work was supported by funding from the National Health and Medical Research Council of Australia (PG1082600) and the Australian Research Council (DP130103207).

Drin, G., Morello, V., Casella, J. F., Gounon, P., and Antonny, B. (2008) Asymmetric tethering of flat and curved lipid membranes by a golgin. Science 320, 670-673. doi: 10.1126/science.1155821

Fogelgren, B., Polgar, N., Lui, V. H., Lee, A. J., Tamashiro, K. K., Napoli, J. A., et al. (2015). Urothelial defects from targeted inactivation of exocyst sec10 in mice cause ureteropelvic junction obstructions. PLOS ONE 10:e0129346. doi: 10.1371/journal.pone.0129346

Follit, J. A., San Agustin, J. T., Xu, F., Jonassen, J. A., Samtani, R., Lo, C. W., et al. (2008). The Golgin GMAP210/TRIP11 anchors IFT20 to the Golgi complex. PLoS Genet. 4:e1000315. doi: 10.1371/journal.pgen.1000315

Foulquier, F., Ungar, D., Reynders, E., Zeevaert, R., Mills, P., García-Silva, M. T., et al. (2007). A new inborn error of glycosylation due to a Cog8 deficiency reveals a critical role for the Cog1-Cog8 interaction in COG complex formation. Hum. Mol. Genet. 16, 717-730. doi: 10.1093/hmg/ddl476

Fridmann-Sirkis, Y., Siniossoglou, S., and Pelham, H. R. (2004). TMF is a golgin that binds Rab6 and influences Golgi morphology. BMC Cell Biol. 5:18. doi: 10.1186/1471-2121-5-18

Friedrich, G. A., Hildebrand, J. D., and Soriano, P. (1997). The secretory protein Sec8 is required for paraxial mesoderm formation in the mouse. Dev. Biol. 192, 364-374. doi: 10.1006/dbio.1997.8727

Gillingham, A. K., Tong, A. H., Boone, C., and Munro, S. (2004). The GTPase Arflp and the ER to Golgi cargo receptor Erv14p cooperate to recruit the golgin Rud3p to the cis-Golgi. J. Cell Biol. 167, 281-292. doi: 10.1083/jcb.2004 07088

Gissen, P., Johnson, C. A., Morgan, N. V., Stapelbroek, J. M., Forshew, T., Cooper, W. N., et al. (2004). Mutations in VPS33B, encoding a regulator of SNARE-dependent membrane fusion, cause arthrogryposis-renal dysfunctioncholestasis (ARC) syndrome. Nat. Genet. 36, 400-404. doi: 10.1038/ng1325

Gleeson, P. A., Lock, J. G., Luke, M. R., and Stow, J. L. (2004). Domains of the TGN: coats, tethers and G proteins. Traffic 5, 315-326. doi: 10.1111/j.13989219.2004.00182.x

Grabski, R., Balklava, Z., Wyrozumska, P., Szul, T., Brandon, E., Alvarez, C., et al. (2012). Identification of a functional domain within the p115 tethering factor that is required for Golgi ribbon assembly and membrane trafficking. J. Cell Sci. 125, 1896-1909. doi: 10.1242/jcs.090571

Grote, E., Carr, C. M., and Novick, P. J. (2000). Ordering the final events in yeast exocytosis. J. Cell Biol. 151, 439-452. doi: 10.1083/jcb.151.2.439

Heider, M. R., and Munson, M. (2012). Exorcising the exocyst complex. Traffic 13, 898-907. doi: 10.1111/j.1600-0854.2012.01353.x

Hirata, T., Fujita, M., Nakamura, S., Gotoh, K., Motooka, D., Murakami, Y., et al. (2015). Post-Golgi anterograde transport requires GARP-dependent endosome-to-TGN retrograde transport. Mol. Biol. Cell 26, 3071-3084. doi: 10.1091/mbc.E14-11-1568

Infante, C., Ramos-Morales, F., Fedriani, C., Bornens, M., and Rios, R. M. (1999). GMAP-210, A cis-Golgi network-associated protein, is a minus end microtubule-binding protein. J. Cell Biol. 145, 83-98. doi: 10.1083/jcb.145.1.83 
Jones, T. A., Nikolova, L. S., Schjelderup, A., and Metzstein, M. M. (2014). Exocystmediated membrane trafficking is required for branch outgrowth in Drosophila tracheal terminal cells. Dev. Biol. 390, 41-50. doi: 10.1016/j.ydbio.2014. 02.021

Kakinuma, T., Ichikawa, H., Tsukada, Y., Nakamura, T., and Toh, B. H. (2004). Interaction between $\mathrm{p} 230$ and MACF1 is associated with transport of a glycosyl phosphatidyl inositol-anchored protein from the Golgi to the cell periphery. Exp. Cell Res. 298, 388-398. doi: 10.1016/j.yexcr.2004.04.047

Katayama, K., Sasaki, T., Goto, S., Ogasawara, K., Maru, H., Suzuki, K., et al. (2011). Insertional mutation in the Golgbl gene is associated with osteochondrodysplasia and systemic edema in the OCD rat. Bone 49, 1027-1036. doi: 10.1016/j.bone.2011.08.001

Kawamura, N., Sun-Wada, G. H., Aoyama, M., Harada, A., Takasuga, S., Sasaki, T., et al. (2012). Delivery of endosomes to lysosomes via microautophagy in the visceral endoderm of mouse embryos. Nat. Commun. 3:1071. doi: 10.1038/ncomms2069

Kierszenbaum, A. L., Rivkin, E., and Tres, L. L. (2008). Expression of Fer testis (FerT) tyrosine kinase transcript variants and distribution sites of FerT during the development of the acrosome-acroplaxome-manchette complex in rat spermatids. Dev. Dyn. 237, 3882-3891. doi: 10.1002/dvdy.21789

Kikukawa, K., Kamei, T., and Suzuki, K. (1989). Study on cause of death in rat neonates with congenital osteochondrodysplasia (ocd/ocd) I. Morphological abnormalities in lung and respiratory tract. Congenit. Anom. 29, 73-82. doi: 10.1111/j.1741-4520.1989.tb00736.x

Kim, S., Hill, A., Warman, M. L., and Smits, P. (2012). Golgi disruption and early embryonic lethality in mice lacking USO1. PLoS ONE 7:e50530. doi: 10.1371/journal.pone.0050530

Kingsley, D. M., Kozarsky, K. F., Segal, M., and Krieger, M. (1986). Three types of low density lipoprotein receptor-deficient mutant have pleiotropic defects in the synthesis of N-linked, O-linked, and lipid-linked carbohydrate chains. J. Cell Biol. 102, 1576-1585. doi: 10.1083/jcb.102.5.1576

Kranz, C., Ng, B. G., Sun, L., Sharma, V., Eklund, E. A., Miura, Y., et al. (2007). COG8 deficiency causes new congenital disorder of glycosylation type IIh. Hum. Mol. Genet. 16, 731-741. doi: 10.1093/hmg/ddm028

Lees, J. A., Yip, C. K., Walz, T., and Hughson, F. M. (2010). Molecular organization of the COG vesicle tethering complex. Nat. Struct. Mol. Biol. 17, 1292-1297. doi: 10.1038/nsmb.1917

Lerer-Goldshtein, T., Bel, S., Shpungin, S., Pery, E., Motro, B., Goldstein, R. S., et al. (2010). TMF/ARA160: a key regulator of sperm development. Dev. Biol. 348, 12-21. doi: 10.1016/j.ydbio.2010.07.033

Lieu, Z. Z., Lock, J. G., Hammond, L. A., La Gruta, N. L., Stow, J. L., and Gleeson, P. A. (2008). A trans-Golgi network golgin is required for the regulated secretion of TNF in activated macrophages in vivo. Proc. Natl. Acad. Sci. U.S.A. 105, 3351-3356. doi: 10.1073/pnas.0800137105

Liewen, H., Meinhold-Heerlein, I., Oliveira, V., Schwarzenbacher, R., Luo, G., Wadle, A., et al. (2005). Characterization of the human GARP (Golgi associated retrograde protein) complex. Exp. Cell Res. 306, 24-34. doi: 10.1016/j.yexcr.2005.01.022

Linstedt, A. D. (2004). Positioning the Golgi apparatus. Cell 118, 271-272. doi: 10.1016/j.cell.2004.07.015

Lo, B., Li, L., Gissen, P., Christensen, H., McKiernan, P. J., Ye, C., et al. (2005). Requirement of VPS33B, a member of the Sec1/Munc18 protein family, in megakaryocyte and platelet alpha-granule biogenesis. Blood 106, 4159-4166. doi: 10.1182/blood-2005-04-1356

Lock, J. G., Hammond, L. A., Houghton, F., Gleeson, P. A., and Stow, J. L. (2005). E-cadherin transport from the trans-Golgi network in tubulovesicular carriers is selectively regulated by golgin-97. Traffic 6, 1142-1156. doi: 10.1111/j.16000854.2005.00349.x

Luo, L., Hannemann, M., Koenig, S., Hegermann, J., Ailion, M., Cho, M. K., et al. (2011). The Caenorhabditis elegans GARP complex contains the conserved Vps51 subunit and is required to maintain lysosomal morphology. Mol. Biol. Cell 22, 2564-2578. doi: 10.1091/mbc.E10-06-0493

Mallard, F., Tang, B. L., Galli, T., Tenza, D., Saint-Pol, A., Yue, X., et al. (2002). Early/recycling endosomes-to-TGN transport involves two SNARE complexes and a Rab6 isoform. J. Cell Biol. 156, 653-664. doi: 10.1083/jcb.200110081

Malsam, J., Satoh, A., Pelletier, L., and Warren, G. (2005). Golgin tethers define subpopulations of COPI vesicles. Science 307, 1095-1098. doi: $10.1126 /$ science. 1108061
Matanis, T., Akhmanova, A., Wulf, P., Del Nery, E., Weide, T., Stepanova, T., et al. (2002). Bicaudal-D regulates COPI-independent Golgi-ER transport by recruiting the dynein-dynactin motor complex. Nat. Cell Biol. 4, 986-992. doi: $10.1038 /$ ncb891

Mesmin, B., Drin, G., Levi, S., Rawet, M., Cassel, D., Bigay, J., et al. (2007). Two lipid-packing sensor motifs contribute to the sensitivity of ArfGAP1 to membrane curvature. Biochemistry 46, 1779-1790. doi: 10.1021/bi062288w

Messler, S., Kropp, S., Episkopou, V., Felici, A., Würthner, J., Lemke, R., et al. (2011). The TGF-beta signaling modulators TRAP1/TGFBRAP1 and VPS39/Vam6/TLP are essential for early embryonic development. Immunobiology 216, 343-350. doi: 10.1016/j.imbio.2010.07.006

Morava, E., Zeevaert, R., Korsch, E., Huijben, K., Wopereis, S., Matthijs, G., et al. (2007). A common mutation in the COG7 gene with a consistent phenotype including microcephaly, adducted thumbs, growth retardation, VSD and episodes of hyperthermia. Eur. J. Hum. Genet. 15, 638-645. doi: 10.1038/sj.ejhg. 5201813

Mori, K., and Kato, H. (2002). A putative nuclear receptor coactivator (TMF/ARA160) associates with hbrm/hSNF2 alpha and BRG-1/hSNF2 beta and localizes in the Golgi apparatus. FEBS Lett. 520, 127-132. doi: 10.1016/S0014-5793(02)02803-X

Munro, S. (2011). The golgin coiled-coil proteins of the Golgi apparatus. Cold Spring Harb. Perspect. Biol. 3:a005256. doi: 10.1101/cshperspect.a005256

Murthy, M., Garza, D., Scheller, R. H., and Schwarz, T. L. (2003). Mutations in the exocyst component Sec5 disrupt neuronal membrane traffic, but neurotransmitter release persists. Neuron 37, 433-447. doi: 10.1016/S08966273(03)00031-X

Nakamura, N., Lowe, M., Levine, T. P., Rabouille, C., and Warren, G. (1997). The vesicle docking protein p115 binds GM130, a cis-Golgi matrix protein, in a mitotically regulated manner. Cell 89, 445-455. doi: 10.1016/S00928674(00)80225-1

Neveling, K., Martinez-Carrera, L. A., Hölker, I., Heister, A., Verrips, A., Hosseini-Barkooie, S. M., et al. (2013). Mutations in BICD2, which encodes a golgin and important motor adaptor, cause congenital autosomaldominant spinal muscular atrophy. Am. J. Hum. Genet. 92, 946-954. doi: 10.1016/j.ajhg.2013.04.011

Ng, B. G., Kranz, C., Hagebeuk, E. E., Duran, M., Abeling, N. G., Wuyts, B., et al. (2007). Molecular and clinical characterization of a Moroccan Cog7 deficient patient. Mol. Genet. Metab. 91, 201-204. doi: 10.1016/j.ymgme.2007.02.011

Oates, E. C., Rossor, A. M., Hafezparast, M., Gonzalez, M., Speziani, F., MacArthur, D. G., et al. (2013). Mutations in BICD2 cause dominant congenital spinal muscular atrophy and hereditary spastic paraplegia. Am. J. Hum. Genet. 92, 965-973. doi: 10.1016/j.ajhg.2013.04.018

Orci, L., Perrelet, A., and Rothman, J. E. (1998). Vesicles on strings: morphological evidence for processive transport within the Golgi stack. Proc. Natl. Acad. Sci. U.S.A. 95, 2279-2283. doi: 10.1073/pnas.95.5.2279

Oztan, A., Silvis, M., Weisz, O. A., Bradbury, N. A., Hsu, S. C., Goldenring, J. R., et al. (2007). Exocyst requirement for endocytic traffic directed toward the apical and basolateral poles of polarized MDCK cells. Mol. Biol. Cell 18, 3978-3992. doi: 10.1091/mbc.E07-02-0097

Peeters, K., Litvinenko, I., Asselbergh, B., Almeida-Souza, L., Chamova, T., Geuens, T., et al. (2013). Molecular defects in the motor adaptor BICD2 cause proximal spinal muscular atrophy with autosomal-dominant inheritance. Am. J. Hum. Genet. 92, 955-964. doi: 10.1016/j.ajhg.2013.04.013

Peng, C., Ye, J., Yan, S., Kong, S., Shen, Y., Li, C., et al. (2012). Ablation of vacuole protein sorting 18 (Vps18) gene leads to neurodegeneration and impaired neuronal migration by disrupting multiple vesicle transport pathways to lysosomes. J. Biol. Chem. 287, 32861-32873. doi: 10.1074/jbc.M112.384305

Peplowska, K., Markgraf, D. F., Ostrowicz, C. W., Bange, G., and Ungermann, C. (2007). The CORVET tethering complex interacts with the yeast Rab5 homolog Vps21 and is involved in endo-lysosomal biogenesis. Dev. Cell 12, 739-750. doi: 10.1016/j.devcel.2007.03.006

Pérez-Victoria, F. J., and Bonifacino, J. S. (2009). Dual roles of the mammalian GARP complex in tethering and SNARE complex assembly at the trans-golgi network. Mol. Cell. Biol. 29, 5251-5263. doi: 10.1128/MCB.00495-09

Perez-Victoria, F. J., Mardones, G. A., and Bonifacino, J. S. (2008). Requirement of the human GARP complex for mannose 6-phosphate-receptor-dependent sorting of cathepsin D to lysosomes. Mol. Biol. Cell 19, 2350-2362. doi: 10.1091/mbc.E07-11-1189 
Polgar, N., Lee, A. J., Lui, V. H., Napoli, J. A., and Fogelgren, B. (2015). The exocyst gene Sec10 regulates renal epithelial monolayer homeostasis and apoptotic sensitivity. Am. J. Physiol. Cell Physiol. 309, C190-C201. doi: 10.1152/ajpcell.00011.2015

Price, A., Wickner, W., and Ungermann, C. (2000). Proteins needed for vesicle budding from the Golgi complex are also required for the docking step of homotypic vacuole fusion. J. Cell Biol. 148, 1223-1229. doi: 10.1083/jcb.148.6.1223

Prigent, M., Dubois, T., Raposo, G., Derrien, V., Tenza, D., Rosse, C., et al. (2003). ARF6 controls post-endocytic recycling through its downstream exocyst complex effector. J. Cell Biol. 163, 1111-1121. doi: 10.1083/jcb.200305029

Puthenveedu, M. A., Bachert, C., Puri, S., Lanni, F., and Linstedt, A. D. (2006). GM130 and GRASP65-dependent lateral cisternal fusion allows uniform Golgienzyme distribution. Nat. Cell Biol. 8, 238-248. doi: 10.1038/ncb1366

Radulescu, A. E., Mukherjee, S., and Shields, D. (2011). The Golgi protein p115 associates with gamma-tubulin and plays a role in Golgi structure and mitosis progression. J. Biol. Chem. 286, 21915-21926. doi: 10.1074/jbc.M110.209460

Ramirez, I. B., and Lowe, M. (2009). Golgins and GRASPs: holding the Golgi together. Semin. Cell Dev. Biol. 20, 770-779. doi: 10.1016/j.semcdb.2009.03.011

Raymond, C. K., Howald-Stevenson, I., Vater, C. A., and Stevens, T. H. (1992). Morphological classification of the yeast vacuolar protein sorting mutants: evidence for a prevacuolar compartment in class E vps mutants. Mol. Biol. Cell 3, 1389-1402. doi: 10.1091/mbc.3.12.1389

Rios, R. M., Sanchis, A., Tassin, A. M., Fedriani, C., and Bornens, M. (2004). GMAP-210 recruits gamma-tubulin complexes to cis-Golgi membranes and is required for Golgi ribbon formation. Cell 118, 323-335. doi: 10.1016/j.cell.2004.07.012

Rios, R. M., Tassin, A. M., Celati, C., Antony, C., Boissier, M. C., Homberg, J. C., et al. (1994). A peripheral protein associated with the cis-Golgi network redistributes in the intermediate compartment upon brefeldin A treatment. J. Cell Biol. 125, 997-1013. doi: 10.1083/jcb.125.5.997

Rivero, S., Cardenas, J., Bornens, M., and Rios, R. M. (2009). Microtubule nucleation at the cis-side of the Golgi apparatus requires AKAP450 and GM130. EMBO J. 28, 1016-1028. doi: 10.1038/emboj.2009.47

Roy, D., Sin, S. H., Damania, B., and Dittmer, D. P. (2011). Tumor suppressor genes FHIT and WWOX are deleted in primary effusion lymphoma (PEL) cell lines. Blood 118, e32-e39. doi: 10.1182/blood-2010-12-323659

Schmitt-John, T., Drepper, C., Mussmann, A., Hahn, P., Kuhlmann, M., Thiel, C., et al. (2005). Mutation of Vps54 causes motor neuron disease and defective spermiogenesis in the wobbler mouse. Nat. Genet. 37, 1213-1215. doi: $10.1038 / \mathrm{ng} 1661$

Schonthaler, H. B., Fleisch, V. C., Biehlmaier, O., Makhankov, Y., Rinner, O., Bahadori, R., et al. (2008). The zebrafish mutant lbk/vam6 resembles human multisystemic disorders caused by aberrant trafficking of endosomal vesicles. Development 135, 387-399. doi: 10.1242/dev.006098

Schwartz, Y., Ben-Dor, I., Navon, A., Motro, B., and Nir, U. (1998). Tyrosine phosphorylation of the TATA element modulatory factor by the FER nuclear tyrosine kinases. FEBS Lett. 434, 339-345. doi: 10.1016/S0014-5793(98)0 1003-5

Seals, D. F., Eitzen, G., Margolis, N., Wickner, W. T., and Price, A. (2000). A $\mathrm{Ypt} / \mathrm{Rab}$ effector complex containing the Sec1 homolog Vps33p is required for homotypic vacuole fusion. Proc. Natl. Acad. Sci. U.S.A. 97, 9402-9407. doi: 10.1073/pnas.97.17.9402

Sevrioukov, E. A., He, J. P., Moghrabi, N., Sunio, A., and Kramer, H. (1999). A role for the deep orange and carnation eye color genes in lysosomal delivery in Drosophila. Mol. Cell 4, 479-486. doi: 10.1016/S1097-2765(00)80199-9

Short, B., Haas, A., and Barr, F. A. (2005). Golgins and GTPases, giving identity and structure to the Golgi apparatus. Biochim. Biophys. Acta 1744, 383-395. doi: 10.1016/j.bbamcr.2005.02.001

Smits, P., Bolton, A. D., Funari, V., Hong, M., Boyden, E. D., Lu, L., et al. (2010). Lethal skeletal dysplasia in mice and humans lacking the golgin GMAP-210. N. Engl. J. Med. 362, 206-216. doi: 10.1056/NEJMoa0900158
Sohda, M., Misumi, Y., Yoshimura, S., Nakamura, N., Fusano, T., Sakisaka, S., et al. (2005). Depletion of vesicle-tethering factor p115 causes mini-stacked Golgi fragments with delayed protein transport. Biochem. Biophys. Res. Commun. 338, 1268-1274. doi: 10.1016/j.bbrc.2005.10.084

Solinger, J. A., and Spang, A. (2013). Tethering complexes in the endocytic pathway: CORVET and HOPS. FEBS J. 280, 2743-2757. doi: 10.1111/febs.12151

Sonnichsen, B., Lowe, M., Levine, T., Jamsa, E., Dirac-Svejstrup, B., and Warren, G. (1998). A role for giantin in docking COPI vesicles to Golgi membranes. J. Cell Biol. 140, 1013-1021. doi: 10.1083/jcb.140.5.1013

Sugimoto, M., Kondo, M., Hirose, M., Suzuki, M., Mekada, K., Abe, T., et al. (2012). Molecular identification of $t(w 5)$ : Vps52 promotes pluripotential cell differentiation through cell-cell interactions. Cell Rep. 2, 1363-1374. doi: 10.1016/j.celrep.2012.10.004

Suzuki, K., Kikukawa, K., and Imamichi, T. (1987). External and skeletal observations on a new lethal mutant of the rat: congenital osteochondrodysplasia with systemic subcutaneous edema. Congenit. Anom. (Kyoto). 27, 69-84. doi: 10.1111/j.1741-4520.1987.tb00696.x

Suzuki, T., Oiso, N., Gautam, R., Novak, E. K., Panthier, J. J., Suprabha, P. G., et al. (2003). The mouse organellar biogenesis mutant buff results from a mutation in Vps33a, a homologue of yeast vps33 and Drosophila carnation. Proc. Natl. Acad. Sci. U.S.A. 100, 1146-1150. doi: 10.1073/pnas.0237292100

Tai, G., Lu, L., Wang, T. L., Tang, B. L., Goud, B., Johannes, L., et al. (2004). Participation of the syntaxin 5/Ykt6/GS28/GS15 SNARE complex in transport from the early/recycling endosome to the trans-Golgi network. Mol. Biol. Cell 15, 4011-4022. doi: 10.1091/mbc.E03-12-0876

Ting, C. H., Wen, H. L., Liu, H. C., Hsieh-Li, H. M., Li, H., and Lin-Chao, S. (2012). The spinal muscular atrophy disease protein SMN is linked to the Golgi network. PLOS ONE 7:e51826. doi: 10.1371/journal.pone.0051826

Whyte, J. R., and Munro, S. (2001). The Sec34/35 Golgi transport complex is related to the exocyst, defining a family of complexes involved in multiple steps of membrane traffic. Dev. Cell 1, 527-537. doi: 10.1016/S1534-5807(01)00063-6

Wong, M., and Munro, S. (2014). Membrane trafficking. The specificity of vesicle traffic to the Golgi is encoded in the golgin coiled-coil proteins. Science 346:1256898. doi: 10.1126/science. 1256898

Wu, X., Steet, R. A., Bohorov, O., Bakker, J., Newell, J., Krieger, M., et al. (2004). Mutation of the COG complex subunit gene COG7 causes a lethal congenital disorder. Nat. Med. 10, 518-523. doi: 10.1038/nm1041

Wurmser, A. E., Sato, T. K., and Emr, S. D. (2000). New component of the vacuolar class C-Vps complex couples nucleotide exchange on the Ypt7 GTPase to SNARE-dependent docking and fusion. J. Cell Biol. 151, 551-562. doi: 10.1083/jcb.151.3.551

Yadav, S., Puri, S., and Linstedt, A. D. (2009). A primary role for Golgi positioning in directed secretion, cell polarity, and wound healing. Mol. Biol. Cell 20, 1728-1736. doi: 10.1091/mbc.E08-10-1077

Yeaman, C., Grindstaff, K. K., Wright, J. R., and Nelson, W. J. (2001). Sec6/8 complexes on trans-Golgi network and plasma membrane regulate late stages of exocytosis in mammalian cells. J. Cell Biol. 155, 593-604. doi: $10.1083 /$ jcb. 200107088

Yu, I. M., and Hughson, F. M. (2010). Tethering factors as organizers of intracellular vesicular traffic. Annu. Rev. Cell Dev. Biol. 26, 137-156. doi: 10.1146/annurev.cellbio.042308.113327

Conflict of Interest Statement: The authors declare that the research was conducted in the absence of any commercial or financial relationships that could be construed as a potential conflict of interest.

Copyright (c) 2016 Toh and Gleeson. This is an open-access article distributed under the terms of the Creative Commons Attribution License (CC BY). The use, distribution or reproduction in other forums is permitted, provided the original author(s) or licensor are credited and that the original publication in this journal is cited, in accordance with accepted academic practice. No use, distribution or reproduction is permitted which does not comply with these terms. 